Methods: A prospective study was conducted on RA patients with newly diagnosed. Patients were evaluated twice, at the time of diagnosis and three months after the initiation of treatment. Demographic data, anthropometric measurements, disease activity scores and sarcopenia status were recorded. Sarcopenia was evaluated with grip strength and bioelectric impedance. The results were also compared with healthy volunteers.

Results: Hand grip strength $(p<0.001)$, skeletal muscle mass $(p=0.009)$ and skeletal muscle mass index $(p=0.032)$ were found to be reduced in RA patients compared to the control group. The frequency of sarcopenia in RA at onset of diagnosis was found to be $31.5 \%$. There was a significant decrease in the rate of sarcopenia after three months of treatment $(31.5 \%$ versus $8.7 \% ; p=0.046)$.

Conclusion: Sarcopenia was found in approximately one third of the patients with newly diagnosed RA in our study. With treatment, sarcopenia improved significantly. RA patients should be evaluated in terms of sarcopenia besides evaluating joint and extra-articular findings at the time of diagnosis. Early detection and treatment planning may improve the quality of life.
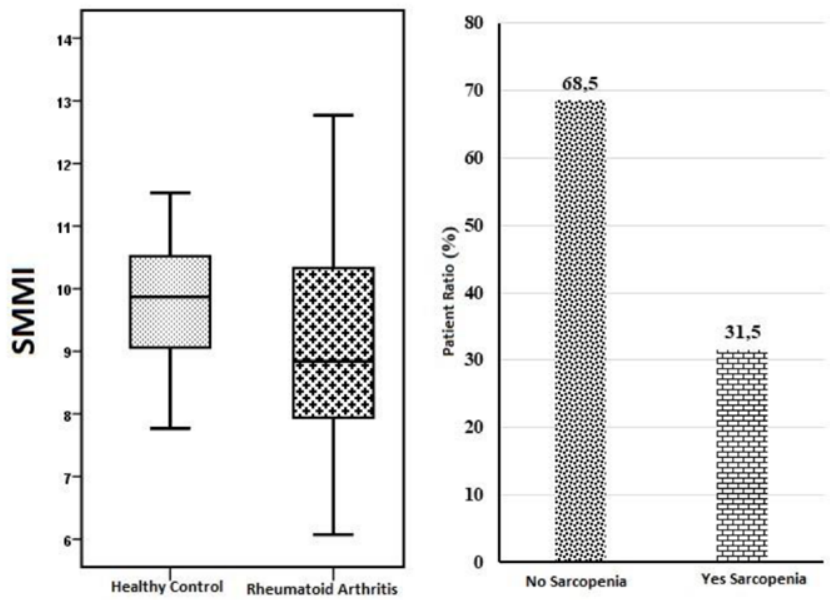

Figure 1. Distribution of skeletal muscle mass index (SMMI) and prevalence of sarcopenia in RA and control groups

Table 1. Demographics, clinical features, anthropometric measurements and disease activity scores of sarcopenic and non-sarcopenic RA patients

\begin{tabular}{|c|c|c|c|}
\hline & $\begin{array}{l}\text { RA without } \\
\text { sarcopenia } \\
n=37\end{array}$ & $\begin{array}{l}\text { RA with } \\
\text { sarcopenia } \\
\mathrm{n}=17\end{array}$ & p \\
\hline Age, mean (SD), years & $47,3(12,8)$ & $58,0(16)$ & $0,011^{*}$ \\
\hline Gender, female, n (\%) & $27(73)$ & $9(52,9)$ & 0,215 \\
\hline Marital status, married, $\mathrm{n}(\%)$ & $34(91,9)$ & $13(76,5)$ & 0,258 \\
\hline \multicolumn{4}{|l|}{ Tobacco consumption, $\mathrm{n}(\%)$} \\
\hline Active smoker & $10(27)$ & $5(29,4)$ & \multirow[t]{3}{*}{0,086} \\
\hline Ex-smoker & $8(21,6)$ & $8(47,1)$ & \\
\hline Never smoker & $19(51,4)$ & $4(23,5)$ & \\
\hline \multicolumn{4}{|l|}{ Alcohol consumption, $\mathrm{n}(\%)$} \\
\hline Active drinker & $2(5,4)$ & $2(11,8)$ & \multirow{3}{*}{0,244} \\
\hline Ex-drinker & $0(0,0)$ & $1(5,9)$ & \\
\hline Never drinker & $35(94,6)$ & $14(82,4)$ & \\
\hline \multicolumn{4}{|l|}{ Occupation, n (\%) } \\
\hline Worker & $15(40,5)$ & $12(70,6)$ & 0,060 \\
\hline Height, mean (SD), meter & $1,6(0,1)$ & $1,6(0,1)$ & 0,664 \\
\hline Weight, mean (SD), kg & $80,6(17,7)$ & $65,3(8,6)$ & $<0,001^{*}$ \\
\hline BMI, mean (SD), $\mathrm{kg} / \mathrm{m}^{2}$ & $31,4(7,3)$ & $24,9(3,2)$ & $<0,001^{*}$ \\
\hline Obese, n (\%) & $20(54,1)$ & $2(11,8)$ & $0,006^{\star}$ \\
\hline Waist circumference, mean (SD), cm & $97,1(14,2)$ & $89,3(12,8)$ & 0,058 \\
\hline Hip circumference, mean (SD), cm & $108,1(12,7)$ & $96,6(5,1)$ & $0,001^{*}$ \\
\hline Calf circumference, mean (SD), cm & $35,4(5,1)$ & $29,6(4,0)$ & $<0,001^{*}$ \\
\hline $\begin{array}{l}\text { Triceps skin thickness, median (min- } \\
\text { max), mm }\end{array}$ & $22(8-36)$ & $15(6-31)$ & $0,022^{*}$ \\
\hline \multicolumn{4}{|l|}{ Loss of muscle strength, $n(\%)$} \\
\hline Right & $10(27,0)$ & $9(52,9)$ & 0,076 \\
\hline Left & $12(32,4)$ & $10(58,8)$ & 0,081 \\
\hline Dominant hand, right, $\mathrm{n}(\%)$ & $33(89,2)$ & $13(76,5)$ & 0,418 \\
\hline SMM, mean (SD) & $25,1(5,8)$ & $21,9(4,7)$ & $0,049^{*}$ \\
\hline SMMI, mean (SD) & $9,6(1,5)$ & $8,2(1,2)$ & $<0,001^{*}$ \\
\hline DAS 28 - CRP, median (min-max) & $4,4(1,7-6,5)$ & $4,4(2,4-6,3)$ & 0,860 \\
\hline SDAI, median (min-max) & $36,1(8,8-113)$ & $31,1(17,1-113)$ & 0,668 \\
\hline CDAl, median (min-max) & $23(0-48)$ & $23(6-39)$ & 0,993 \\
\hline PrGA, median (min-max) & $6(0-9)$ & $5(2-10)$ & 0,627 \\
\hline PtGA, median (min-max) & $8(0-10)$ & $7(4-10)$ & 0,666 \\
\hline Presence of morning stiffness, $n(\%)$ & $32(86,5)$ & $14(82,4)$ & 0,999 \\
\hline Swollen joint count, median (min-max) & $2(0-10)$ & $4(0-9)$ & 0,423 \\
\hline Tender joint count, median (min-max) & $6(0-20)$ & $7(0-18)$ & 0,911 \\
\hline
\end{tabular}

Disclosure of Interests: None declared

DOI: 10.1136/annrheumdis-2021-eular.1874

\section{AB0158 \\ COMPARISON OF CLINICAL EXAMINATION AND ULTRASOUND OF HAND AND WRIST JOINTS IN RHEUMATOID ARTHRITIS}

S. Bouden ${ }^{1}$, B. D. Siwar ${ }^{1}$, A. Ben Tekaya ${ }^{1}$, O. Saidane ${ }^{1}$, R. Tekaya ${ }^{1}$,

I. Mahmoud ${ }^{1}$, L. Abdelmoula ${ }^{1} .{ }^{1}$ Charles Nicolle Hospital, Department of Rheumatology, Tunis, Tunisia

Background: Ultrasound (US) is an accessible and non-invasive tool to assess joint involvement in rheumatoid arthritis (RA). It is used for diagnostic and prognosis purposes and for following of RA patients by evaluating the disease activity and therefore the response to treatment.

Objectives: This study investigates agreement between US of hand and wrist findings and the clinical examination and biological inflammatory parameters in RA patients.

Methods: We performed a cross sectional study including patients responding to the ACR/EULAR 2010 criteria for RA diagnosis. We collected US findings assessing synovitis and doppler signal in wrist, metacarpophalangeal (MCP) and proximal interphalangeal (PIP) articulations, and concomitant clinical examination assessing synovitis and pain in the same joints along with $C$ reactive protein (CRP) levels and disease activity score (DAS28). The power Doppler US score (PDUS) from 6 simplified synovial sites (wrists, bilateral second and third MCP joints) was calculated [1].

Results: Forty-three patients were included with $91.7 \%$ of women. The mean age was $62 \pm 12.95$ years old. The mean age at diagnosis was $52 \pm 14.79$ years with a mean disease evolution of $8 \pm 8.57$ years. Rheumatoid factor and anti-citrullinated antibodies were positive in respectively $78 \%$ and $83.9 \%$ of cases.

The mean disease activity (DAS28) was 1,52 with levels ranging from 1.5 to 7.33. Right wrist was the articulation in which US synovitis was most frequently detected (60.5\% of patients), followed by the left wrist (53.5\%). Power doppler signal was detected as frequently in the right as in the left wrist articulations (41.9\%). Subsequently, clinical synovitis was most frequently detected in right and left wrist with $39,5 \%$ and $41,5 \%$ respectively. These joints were the most frequently painful, in $51.2 \%$ and $48.8 \%$ at right and left respectively.

US synovitis of the first interphalangeal joint was found in only $2.3 \%$ and $4.7 \%$ in the right and left hand respectively, with positive power doppler signal in $2.3 \%$ of the patients in the same articulations.

The overall agreement between US and clinical examination in detecting synovitis of wrist, MCP and PIP joints was of $67.3 \%$. It was of $71.4 \%$ in wrists, $54.7 \%$ in MCP joints and $87 \%$ in PIP joints. This suggests the presence of infra-clinical synovitis. All sites combined, US synovitis were correlated to clinical synovitis $(p=0.03)$.

A positive correlation was found between PDUS from 6 simplified joint sites and CRP levels ( $p$ value of 0.02 ). No correlation was found with disease activity score (DAS28).

Conclusion: US of hands and wrist articulations is more performant than clinical examination in detecting synovitis. The most frequently involved joints with clinical and US synovitis, pain and positive power doppler signal were the wrist joints. CRP level is predictive of the presence of a high simplified power doppler score which is related to clinical activity of the disease as reported by Kawashiri et al. [1].

\section{REFERENCES:}

[1] Kawashiri S, Kawakami A, Iwamoto N, Fujikawa K, Satoh K, Tamai M, et al. The power Doppler ultrasonography score from 24 synovial sites or 6 simplified synovial sites, including the metacarpophalangeal joints, reflects the clinical disease activity and level of serum biomarkers in patients with rheumatoid arthritis. Rheumatology (Oxford). mai 2011;50(5):962-5.

Disclosure of Interests: None declared

DOI: 10.1136/annrheumdis-2021-eular.1922

\section{AB0159 DIASTOLIC DYSFUNCTION IN PATIENTS WITH RHEUMATOID ARTHRITIS}

S. Cabrera-Villalba ${ }^{1}$, V. Valinotti ${ }^{1}$, L. Roman ${ }^{1}$, A. Paats ${ }^{1}$, P. DE Abreu Trigueros ${ }^{2}$, M. Duarte ${ }^{1}$, T. Martinez ${ }^{3}$, I. Acosta-Colman ${ }^{1}$, G. Avila ${ }^{1}$, O. Centurion ${ }^{4} .{ }^{1}$ Clinicas Hospital, Universidad Nacional de Asuncion, Rheumatology, San Lorenzo, Paraguay; ${ }^{2}$ Sociedad Paraguaya de Reumatolog ía, Rheumatology, Asunción, Paraguay; ${ }^{3}$ Asunción, Laboratorio Curie, Asunción, Paraguay; ${ }^{4}$ Clinicas Hospital, Universidad Nacional de Asuncion, Cardiovascular Medicine, Asunción, Paraguay

Background: Rheumatoid arthritis (RA) presents with an elevated incidence of congestive heart failure disease, which has a strong association with diastolic dysfunction, defined by left ventricular delayed relaxation pattern assessed by echocardiography. $(1,2)$

Objectives: To describe the frequency of left ventricular delayed relaxation pattern in patients with RA, and the relationship with its clinical and serologica characteristics, as well as with traditional and non-traditional cardiovascular risk factors. 